\title{
RETURNING TO THE ORTHODONTIC PRACTICE AMID COVID-19 CRISIS
}

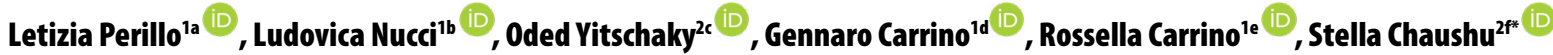 \\ ${ }^{1}$ Multidisciplinary Department of Medical-Surgical and Dental Specialties, School of Dentistry, University of Campania Luigi Vanvitelli, Naples, Italy \\ ${ }^{2}$ Department of Orthodontics, Faculty of Dental Medicine, Hebrew University-Hadassah, Jerusalem, Israel \\ aMD, MS, PhD, Professor, Head, Dean; e-mail: letizia.perillo@unicampania.it; ORCIDiD: https://orcid.org/0000-0001-6175-7363 \\ bDDS, PhD Student; e-mail: ludortho@gmail.com; ORCIDiD: https://orcid.org/0000-0002-7174-7596 \\ 'DMD, MA; e-mail: oyits76@gmail.com; ORCIDiD: https://orcid.org/0000-0002-5732-532X \\ dMD, MS, PhD; e-mail: gencarrino@gmail.com; ORCIDiD: https://orcid.org/0000-0002-9179-0751 \\ eDDS, Postgraduate Student; e-mail: rossella.carrino1@gmail.com; ORCIDiD: https://orcid.org/0000-0003-0417-5791 \\ fDMD, MSc, PhD; e-mail: drchaushu@hadassah.org.il; ORCIDiD: https://orcid.org/0000-0001-9571-8338
}

\section{ABSTRACT}

de) https://doi.org/10.25241/stomaeduj.2020.7(3).art.7

Background The coronavirus disease (COVID-19), caused by the novel severe acute respiratory virus syndrome (SARS)-CoV-2, was defined as pandemic on March 11, 2020. All health care providers are at risk of a COVID-19 infection; however, dentists pose the highest risk since SARS-CoV-2 is transmitted through breathing and aerosol, coughing and droplets and direct or indirect contact with infected skin and surfaces. Guidelines for minimizing the risk of transmission in general dental clinics have been published and are regularly updated. Objective The present article aims to specifically address the concerns of the orthodontic profession amid the COVID-19 crisis, and suggest recommendations for orthodontic care settings, infection prevention measures and delivery of clinical procedures.

Data Sources An electronic search was conducted via PubMed/MEDLINE, Google and health organization websites from two independent data abstractors.

Study Selection All kinds of manuscripts describing guidelines for health care providers to follow during the COVID-19 pandemic were included. No language restrictions were considered. Any disagreements on study inclusion were resolved by discussion between the two reviewers.

Data Extraction Information on guidelines and suggestions on the management of clinical orthodontic practice were extracted from studies identified for inclusion in the review.

Data Synthesis Orthodontists are at a very high risk for COVID-19 infection and all published guidelines should be followed for the patient and DHCPs safety. The care settings, the infection protocols, and the delivery of AGP clinical procedures must be continuously revised and modified to overcome the threat of the SARS-CoV-2 infection in the orthodontic practice.

\section{KEYWORDS}

COVID-19; Saliva; Aerosol; Orthodontists; Clinical Practice.

\section{INTRODUCTION}

The coronavirus disease 2019 (COVID-19) is a clinical syndrome caused by the novel Severe Acute Respiratory Syndrome Coronavirus 2 (SARS-CoV-2), a pathogen closely related to the Severe Acute Respiratory Syndrome Coronavirus (SARS-CoV) and Middle East Respiratory Syndrome Related Coronavirus (MERS-
CoV). SARS-CoV-2 mainly attacks the respiratory system, due to its affinity to angiotensin-converting enzyme 2 (ACE2) cell receptor, highly expressed in the lungs and the heart [1]. COVID-19 appears to have a lower case-fatality rate (3.4\%) as compared to SARSCoV (10\%) and MERS-CoV (3.4\%) [2], but is more transmissible, therefore posing a major public health threat. Most people infected by COVID-19 present

Received: July 03, 2020; Revised: July 20, 2020; Accepted: July 21, 2020; Published: July 23, 2020

*Corresponding author: Prof. Dr. Stella Chaushu, Professor and Chair, Department of Orthodontics, Faculty of Dental Medicine, Hebrew UniversityHadassah, Jerusalem, Israel, Address: PO Box 12272

Tel.: 972-2-6776184; Fax: 972-2-6427613; e-mail: drchaushu@hadassah.org.il

Copyright: $\odot 2020$ the Editorial Council for the Stomatology Edu Journal. 
mild, inconsequential respiratory symptoms. However, a minority of often aged individuals with other medical conditions, develop a severe disease, clearly distinct from the well-known acute respiratory distress syndrome. The disease is caused by a cytokine storm, a form of systemic unrestrained inflammatory response featured by the abundant release of proinflammatory cytokines [3].

This leads to alveolar injury, increased vascular permeability and extravascular accumulation of edema fluid, culminating in respiratory and heart failure, thromboembolism and death [4]. COVID-19 was declared as a pandemic by the World Health Organization (WHO) on March 11, 2020.

The current approaches to treatment include vaccine development and discovering new or re-proposed anti-viral and immunosuppressive medicines [5]. Unfortunately, pharmacologic treatments and vaccines are not yet available and it is likely that a high number of asymptomatic carriers [6] contribute to the spread of the virus. Currently, isolation and social distancing seem to be the most effective weapons against the virus and its widespread [7].

In this gruesome scenario, health care providers are extremely vulnerable and among them, dentists are considered to be at the highest risk [8], although the exact risk is still unknown. SARS-CoV-2 is transmitted by droplets loaded with viral particles emitted from the respiratory tract of an infected individual.

Dentists come in close contact with the oral cavity and are exposed to aerosol from breathing and coughing. Furthermore, droplets land on surfaces and can spread infection in the dental office by direct or indirect contact [9].

Dental care procedures may also aerosolize viral particles from saliva during treatment in the same way as sneezing or coughing. Dental aerosol generating procedures (AGPs) are associated with the use of ultrasonic instruments, air/water syringe and handpieces [10]. They have been charged to be responsible for the virus transmission and infection for healthy patients, but at the same time, they also represent a high risk for the dental health care personnel (DHCP) [11].

AGPs can generate droplets having a diameter ranging from $0.1 \mu \mathrm{m}$ to $900 \mu \mathrm{m}$. Liu Y, et al classified the droplets in five groups, with the largest group ranging from $0.25 \mu \mathrm{m}$ to $1 \mu \mathrm{m}$ [12]. The particles with this diameter can reach the alveoli. Droplets $<0.25 \mu \mathrm{m}$, loaded with pathogenic microorganisms, can travel up to 20 feet [13], so the 1-2-meter distance advised by WHO is not always enough to prevent cross infection between patients and DHCP.

The minimal aerosol viral load necessary for infection is still unknown; However, in vitro experiments show that aerosol contains viable virus for up to 16 hours [14]. Infectiveness of aerosol finds the evidence when COVID-19 gave an outbreak in buses and conference rooms [15]. Treatment sessions on the dentist chair should be divided into two risk categories: with AGP and without AGP. Each of them must be faced with proper Personal Protective Equipment (PPE) [13]. The Centers for Disease Control and Prevention (CDC) recommended using N95 respirators and not surgical face masks, whenever AGPs are performed [7].

Moreover, if AGP are needed for patients who have or are suspected of having COVID-19, airborne precautions should be strictly followed in addition to adequate PPE and a room with negative pressure, relative to the surrounding area, becomes mandatory [16]. Unfortunately, at this moment, there is still no reliable and efficient test to identify asymptomatic carriers, therefore everybody should be suspected to be infective. Caprioglio et al. published an interesting editorial article on the management of orthodontic emergencies during the initial quarantine period, of COVID-19 pandemics [17].

Recently, the American Dental Association (ADA) has published interim guidelines for minimizing the risk of COVID-19 transmission [18]. There are essential recommendations for all dental practitioners and clearly they should be followed by orthodontists. However, orthodontic treatment is different, since emergency service is seldom required [17], and many orthodontic procedures do not generate AGP.

Moreover, many treatment protocols can be modified to decrease droplets production and thus minimize the risk of cross contamination in the orthodontic office.

The aim of this article is to focus on the orthodontic profession and suggest specific recommendations for care settings, infection control and treatment delivery amid the COVID-19 crisis. The article was written as an international cooperation between the University of Campania Luigi Vanvitelli, Naples, Italy, and the Hebrew University-Hadassah Faculty of Dental Medicine, Jerusalem, Israel.

\section{ORTHODONTIC PRACTICE AND COVID-19}

\subsection{Before orthodontic treatment}

- An orthodontic practice usually has a high patient turnover, including a mixture of children and adults. Scheduling of appointments should allow appropriate "social distancing" in the waiting room.

Adults should be instructed to come without companions; however, children are usually accompanied by guardians. In this case, pretreatment triage for signs and symptoms of COVID-19 should be performed for both children and guardians.

DHCP will collect the medical history and check temperature to identify suspect patients until reliable chairside tests for SARS-CoV-2 are developed [19]. Since the virus has been found on shoes, a shoe wrapping machine can be installed at the entrance. Toys, books and other items which may carry the virus have to be removed from the waiting room.

- The recall orthodontic appointments are usually short. Due to the time needed for room cleaning and disinfection, working on a single chair is extremely 
inefficient, whereas working on at least 2 chairs, alternating working and disinfection, is preferred. The minimal distance between the chairs is 2 meters and a separation box is needed as a physical barrier to minimize aerosol spreading [20].

- Implementing tele dental applications can be particularly advantageous in this period. Records assessment and proposed treatment plans can be shared virtually online with the patients and discussed using modern web-based communication tools [21]. All communication with patients through virtual tools should be documented in the patients' file for medicolegal protection, as any physical appointment.

- ADA recommended antibacterial mouth rinses ( $1.5 \%$ hydrogen peroxide) before treatment, to reduce the viral load, but there are no clinical studies to support it. Mouth rinses containing $\beta$-cyclodextrins combined with flavonoids agents have been proposed for COVID-19 [22]. Children should rinse only under adult supervision.

\subsection{During the orthodontic treatment}

The CDC divides patient-care items in 3 categories: critical, semi critical, and noncritical, depending on the potential risk for infection. Critical items have the greatest risk for transmitting infection and should always be sterilized using heat [23].

This classification takes in consideration the risk of bloodborne contamination. However, the transmission modes of SARS-CoV-2 are respiratory droplets and physical contact [10]. Under these circumstances, each item that has been in contact with the patient or maybe contaminated by aerosol, becomes critical. 2.2.1. Records collection

- Extraoral radiographs, such as panoramic views, should be preferred whenever possible since intraoral radiographs may cause saliva secretion and coughing [19].

- Clinical photos should be taken wearing clean gloves, masks, and glasses, since cameras are difficult to clean and disinfect. Double gloving allows handling the camera with the inner gloves, after discarding the outer gloves.

Anti-fog treatment of mirrors should be done with warm water and not with air. Assistants should handle the plastic retractor and the mirror, thus fourhanded orthodontics is mandatory [24]. The plastic retractor and the mirror should be autoclaved after use. An antibacterial cloth can be used for cleaning the camera surface.

- Dental impressions are potential sources of contamination through the adhered blood or saliva. ADA [19], CDC [24] require impression disinfection to prevent contamination. Irreversible hydrocolloid impressions are effectively treated with 1:10 dilution of sodium hypochlorite for a ten-minute immersion [25]. Disposable impression trays should not be reprocessed since they are manufactured for a single use or for the use of one patient only, and not designed or intended for reuse [26].
- Intraoral scanning should be preferred whenever possible, especially for study models. Scanning does not reduce chair-time, but is more comfortable for the patient, minimizing gag reflex and difficulties in breathing associated with conventional impressions [27]. Moreover, the intraoral tip of the scanner is autoclavable.

\subsubsection{Multibracket appliances}

- Bonding requires etching of the enamel. Air/water syringe is used to wash and dry the enamel after etching, as well as to spread the bonding resin into a thin layer before light curing. ADA is advocating the use of a rubber dam for AGPs, to help minimize aerosol or splatter, as the saliva is washed away from teeth and aspirated with high power suction, before drying with the air syringe [11].

The use of a rubber dam in orthodontics has been already proposed for bracket bonding in general anesthesia [28] and can be also adopted in the routine orthodontic practice. Conversely, a rubber dam can introduce errors in bracket positioning, which can be avoided by using indirect bonding techniques or drawing marks on the teeth.

- Self-etching primer, which eliminates the need for air/water spray washing and drying, is an excellent alternative to the two-step conventional bonding techniques.

The bond strength with self-etching primers is clinically acceptable and bonding duration is also slightly reduced [29].

- Indirect bonding is an additional option which can significantly shorten chair-time, by up to $30 \mathrm{~min}$ for both arches [30] and reduce the DHCP exposure.

Thus, a combination of self-etching primer and indirect bonding significantly decreases the risk of aerosol contamination during bonding procedures.

- Visible-light curing units are a potential source of transmission due to contamination of the light curing tip, which directly contacts oral structures, and the handle, which becomes contaminated with blood and saliva from the DHCP gloves.

Different infection control techniques, that meet the CDC-recommended standards, include sterilization of curing tips, disposable barriers, or single-use plastic wrapping tip [31].

\subsubsection{Removable appliances}

Managing removable appliances in the clinic creates a low risk for the transmission of SARS-CoV-2 [17]. Impressions for appliances should be delivered to the lab after proper disinfection [see above] and returned from the lab after ultraviolet (UV) sterilization [32] in a plastic bag sealed with a label.

\subsubsection{Other orthodontic procedures}

Inserting, tying, and removing archwires and/or miniscrews are not AGPs and may be performed with the conventional ADA interim precautions [18].

\subsubsection{Aligners}

Compared with fixed appliances, aligners offer the advantage of shorter chair-time and fewer overall appointments in the office, therefore decreasing the 
risk for airborne transmission. Whenever possible, treatment progress can be assessed, and further instructions can be given through online virtual meetings. Attachments can be bonded with the aid of self-etching primers similarly to bracket bonding [33] and refined manually. On the contrary, attachment removal, like bracket debonding, is riskless only if a rubber dam is utilized.

\subsubsection{Interproximal enamel reduction}

Instruments used to slenderize teeth usually include diamond disks or air rotor burs [34,35]. These methods inevitable create aerosol.

Manual interproximal enamel reduction with handoperated abrasive strips is more time consuming and harder to use in posterior teeth, however it creates less aerosol and should be preferred in this period. Strip holders may aid in manual interproximal reduction [36].

\subsubsection{Auxiliaries}

Elastomeric ligatures, coils or other auxiliaries can be cut in small pieces, inserted in pouches before treatment and delivered to the doctor by the dental assistant. However, in case they are mistakenly contaminated, the unused parts can be sterilized via cold sterilization. Disinfection of these materials in a $2 \%$ glutaraldehyde solution for 10 minutes has no effect on strength and distention [38].

\subsubsection{Band application and removal}

No particular restriction is advised for these procedures, except for the use of air/water syringe. If used and tried on in the mouth, bands should be sterilized in autoclave. When bands are removed, cement breaks away and there is no need to use a handpiece.

\subsection{End of orthodontic treatment}

\subsubsection{Bracket debonding}

Debonding and enamel cleanup is the orthodontic procedure which produces the highest amount of aerosol and splatters [39]. Usually, brackets are debonded with special task pliers, but the adhesive remnants are removed with high speed or low speed burs, discs, or ultrasonic scalers [40]. Dental dam can prevent aerosol creation [10]. Remnants of bonding material can also be removed manually, using adhesive removing pliers, although this method is more time consuming and less efficient, leaving more adhesive remnants on the teeth [41]. The use of ceramic brackets should be restrained for their frequent fracture during debonding and the consequent need to use a turbine handpiece.

\subsubsection{Retainers}

Previous articles reported the bonding of retainers with a rubber dam in order to prevent failures [42]. During the current period, the rubber dam is even more recommended. Self-etching primers and indirect bonding [43] can further shorten chair-time and lower the risk of aerosol exposure, as explained above. Alternatively, clear retainers can be performed using intraoral scans and fixed retainer bonding postponed at this stage.

\section{STERILIZATION OF ORTHODONTIC PLIERS}

Orthodontic pliers touch patients' mucosa/skin and therefore become critical items in the COVID-19 era, and must be sterilized by autoclave. Pliers should be maintained in sterile envelopes, opened just before their use.

A larger supply of instruments is thus mandatory and if a plier is heat-sensitive, it should be replaced by a heat-tolerant item. On the other hand, heat sterilization leads to less corrosion than cold disinfection [37].

\section{CONCLUSIONS}

Similarly to other dental professions, orthodontists are at a very-high-risk for COVID-19 infection, and all published guidelines should be followed for the patient's and DHCP's safety. In the past, DHCP protection measures mostly addressed bloodborne infections. Presently, protection from COVID-19, which is highly transmissible through aerosol, droplets, and contact, is the main global concern.

In this period, the care settings, the infection protocols, and the delivery of AGP clinical procedures must be revised and modified to overcome the threat of SARS-CoV-2 infection in the orthodontic practice.

\section{List of abbreviations}

COVID-19 - Coronavirus disease 2019

(SARS-CoV-2) - Severe Acute Respiratory Syndrome Coronavirus 2 SARS-CoV - Severe Acute Respiratory Syndrome Coronavirus MERS-CoV - Middle East Respiratory Syndrome Related Coronavirus

ACE2 - angiotensin-converting enzyme 2

WHO - World Health Organization

AGP - dental aerosol generating procedure

DHCP - dental health care personnel

PPE - Personal Protective Equipment

CDC - Centers for Disease Control and Prevention

ADA - American Dental Association

UV - ultraviolet

Declarations

- Ethical Approval and Consent to participate - not applicable - Consent for publication - all authors read and approved the final version of the manuscript.

- Availability of supporting data - not applicable

- Competing interests - the authors declare that they have no competing interests.

- Funding - not applicable

- Acknowledgements not applicable

\section{CONFLICT OF INTEREST}

The authors declare no conflict of interest.

\section{AUTHOR CONTRIBUTIONS}

LP, SC and GC conceived the protocol, wrote, and revised the manuscript. LN, RC and OY revised the literature and collected the references. 


\section{REFERENCES}

1. Vaduganathan $\mathrm{M}$, Vardeny $\mathrm{O}$, Michel $\mathrm{T}$, et al. Renin-angiotensinaldosterone system inhibitors in patients with Covid-19. N Engl J Med. 2020;382(17):1653-1659. doi:10.1056/NEJMsr2005760. [Full text links] [CrossRef] [PubMed] [Google Scholar] [Scopus] 2. World Health Organization. Coronavirus disease (Covid-2019) situation reports. Available from: https://www.who.int/ emergencies/diseases/novel-coronavirus-2019/situation-reports [Internet]

3. McGonagle D, Sharif K, O'Regan A, Bridgewood C. The role of cytokines including interleukin-6 in Covid-19 induced pneumonia and macrophage activation syndrome-like disease. Autoimmun Rev. 2020;19(6):102537. doi:10.1016/j. autrev.2020.102537

[Full text links] [CrossRef] [PubMed] [Google Scholar] [Scopus] 4. Driggin E, Madhavan MV, Bikdeli B, et al. Cardiovascula considerations for patients, health care workers, and health systems during the Covid-19 pandemic. J Am Coll Cardiol. 2020;75(18):2352-2371. doi:10.1016/j.jacc.2020.03.031. [Full text links] [PubMed] [Google Scholar] [Scopus] 5. Stebbing J, Phelan A, Griffin I, et al. Covid-19: combining antiviral and anti-inflammatory treatments. Lancet Infect Dis. 2020;20(4):400-402. doi:10.1016/S1473-3099(20)30132-8. [Full text links] [CrossRef] [PubMed] [Google Scholar] [Scopus] 6. Yu X, Yang R. Covid-19 transmission through asymptomatic carriers is a challenge to containment. Influenza Other Respir Viruses. 2020;14(4):474-475 doi:10.1111/irv 12743. [Full text links] [CrossRef] [PubMed] [Google Scholar] 7. Forrester JD, Nassar AK, Maggio PM, Hawn MT. Precautions for operating room team members during the Covid-19 pandemic. J Am Coll Surg. 2020;230(6):1098-1101. doi:10.1016/J. jamcollsurg.2020.03.030.

[Full text links] [CrossRef] [PubMed] [Google Scholar] [Scopus] 8. OSHA. Guidance on Preparing Workplaces for Covid-19. Available from: https://www.osha.gov/Publications/OSHA3990. pdf [Internet]

9. Lai CC, Shih TP, Ko WC, et al. Severe acute respiratory syndrome coronavirus 2 (SARS-CoV-2) and coronavirus disease-2019 (COVID-19): the epidemic and the challenges. Int J Antimicrob Agents. 2020;55(3):105924. doi:10.1016/j. ijantimicag.2020.105924

[Full text links] [CrossRef] [PubMed] [Google Scholar] 10. Harrel SK, Molinari J. Aerosols and splatter in dentistry: a brief review of the literature and infection control implications. J Am Dent Assoc. 2004;135(4):429-437. doi:10.14219/jada. archive.2004.0207.

[Full text links] [CrossRef][PubMed] [Google Scholar] [Scopus] [WoS]

11. Morawska L, Cao J. Airborne transmission of SARS-CoV-2: the world should face the reality. Environ Int. 2020;139:105730. doi:10.1016/j.envint.2020.105730.

[Full text links] [CrossRef] [PubMed] [Google Scholar] [Scopus] 12. Liu Y, Ning Z, Chen Y, et al. Aerodynamic analysis of SARSCoV-2 in two Wuhan hospitals. Nature. 2020;582(7813):557-560. doi:10.1038/s41586-020-2271-3.

[Full text links] [CrossRef] [Google Scholar]

13. Froum S, Strange M. Covid-19 and the problem with denta aerosols. Perio-Implant Adv. Published 2020, April 7th. Available from: https://www.perioimplantadvisory.com/periodontics/ oral-medicine-anesthetics-and-oral-systemic-connection/ article/14173521/covid19-and-the-problem-with-dental-aerosols [Full text links]

14. Fears AC, Klimstra WB, Duprex $P$, et al. Comparative dynamic aerosol efficiencies of three emergent coronaviruses and the unusual persistence of SARS-CoV-2 in aerosol suspensions. Preprint. medRxiv. 2020;2020.04.13.20063784. doi:10.1101/2020. 04.13.20063784.

[Full text links] [CrossRef] [PubMed] [Google Scholar] 15. Shen Y, Li C, Dong H, et al. Airborne transmission of Covid-19: epidemiologic evidence from an outbreak investigation. Preprin April 2020. Available at SSRN: https://ssrn.com/abstract= or http://dx.doi.org/10.2139/ssrn.3567505 doi: 10.13140/ RG.2.2.3665.38881

[Full text links] [CrossRef] [Google Scholar]

16. Banaee S, Claiborne DM, Akpinar-Elci M. Use of negative pressure isolation in the provision of dental care. Decisions in Dentistry. Published 2020, April 13. Available from: https:// decisionsindentistry.com/2020/04/use-of-negative-pressureisolation-in-the-provision-of-dental-care/. [Full text links]
17. Caprioglio A, Pizzetti GB, Zecca PA, et al Management of orthodontic emergencies during 2019-NCOV. Prog Orthod. 2020;21(1):10. doi:10.1186/s40510-020-00310-y. [Full text links] [CrossRef] [PubMed] [Google Scholar] [Scopus] 18. Versaci MB. ADA releases interim guidance on minimizing Covid-19 transmission risk when treating dental emergencies. Resources discuss how to proceed before, during, after treatment. ADA News. Published 2020, April 01. Available from: https://www.ada.org/en/publications/adanews/2020-archive/april/ada-releases-interim-guidanceon-minimizing-covid-19-transmission-risk-when-treatingemergencies [Internet]

19. Sri Santosh T, Parmar R, Anand H, et al. A review of salivary diagnostics and its potential implication in detection of Covid-19. Cureus. 2020;12(4):e7708 doi:10.7759/cureus.7708.

[Full text links] [CrossRef] [PubMed] [Google Scholar] 20. Vilarinho Oliveira AMA, de Alencar RM, Santos Porto JC, et al. Analysis of fungi in aerosols dispersed by high speed pens in dental clinics from Teresina, Piaui, Brazil. Environ Monit Assess. 2018;190(2):56. doi:10.1007/s10661-017-6436-y. [Full text links] [CrossRef] [PubMed] [Google Scholar] [Scopus] [WoS

21. Patel RN, Antonarakis GS. Factors influencing the adoption and implementation of teledentistry in the UK, with a focus on orthodontics. Community Dent Oral Epidemiol. 2013;41(5):424431. doi:10.1111/cdoe.12029. [Full text links] [CrossRef] [PubMed] [Google Scholar] [Scopus] [WoS]

22. Carrouel F, Conte MP, Fisher J, et al. Covid-19: a recommendation to examine the effect of mouthrinses with $\beta$-cyclodextrin combined with Citrox in preventing infection and progression. J Clin Med. 2020;9(4):1 126. doi:10.3390/jcm9041126. [Full text links] [CrossRef] [PubMed] [Google Scholar]

23. Centers for Disease Control and Prevention. Guide to infection prevention for outpatient settings: minimum expectations for safe care. Available from: https://www.cdc.gov/ hai/settings/outpatient/outpatient-care-guidelines.html. Internet

24. Modi PD, Nair G, Uppe A, et al. Covid-19 awareness among healthcare students and professionals in Mumbai metropolitan region: a questionnaire-based survey. Cureus. 2020;12(4):e7514. doi:10.7759/cureus.7514.

25. Schwartz RS, Bradley DV Jr, Hilton TJ, Kruse SK. Immersion disinfection of irreversible hydrocolloid impressions. Part 1: Microbiology. Int J Prosthodont. 1994;7(5):418-423. [Full text links] [PubMed] [Google Scholar] [Scopus] 26. OSAP. FAOIE2018. FAO-Instruments \& Equipment. Available from: https://www.osap.org/page/FAQIE2018 [Internet]

27. Glisic O, Hoejbjerre L, Sonnesen L. A comparison of patient experience, chair-side time, accuracy of dental arch measurements and costs of acquisition of dental models. Angle Orthod. 2019;89(6):868-875. doi:10.2319/020619-84.1.

[Full text links] [CrossRef] [PubMed] [Google Scholar] [Scopus] 28. Chaushu S, Zeltser R, Becker A. Safe orthodontic bonding for children with disabilities during general anaesthesia. Eur $J$ Orthod. 2000;22(3):225-228. doi:10.1093/ejo/22.3.225

[Full text links] [CrossRef] [PubMed] [Google Scholar] [Scopus] [WoS]

29. Fleming PS, Johal A, Pandis N. Self-etch primers and conventional acid-etch technique for orthodontic bonding: a systematic review and meta-analysis. Am J Orthod Dentofacial Orthop. 2012;142(1):83-94. doi:10.1016/j.ajodo.2012.02.023. [Full text links] [CrossRef] [PubMed] [Google Scholar] [Scopus] [WoS]

30. Yıldırım K, Saglam-Aydinatay B. Comparative assessment of treatment efficacy and adverse effects during nonextraction orthodontic treatment of Class I malocclusion patients with direct and indirect bonding: a parallel randomized clinical trial. Am J Orthod Dentofacial Orthop. 2018;154(1):26-34.e1. doi:10.1016/j.ajodo.2017.12.009.

[Full text links] [CrossRef] [PubMed] [Google Scholar] [Scopus] [WoS]

31. Khode RT, Shenoi PR, Kubde RR, et al. Evaluation of effect of different disposable infection control barriers on light intensity of light-curing unit and microhardness of composite - An in vitro study. J Conserv Dent. 2017;20(3):180-184. doi:10.4103/JCD. JCD 17116

[Full text links] [CrossRef] [PubMed] [Google Scholar] [Scopus] 
32. Darnell ME, Taylor DR. Evaluation of inactivation methods for severe acute respiratory syndrome coronavirus in noncellular blood products. Transfusion. 2006;46(10):1770-1777. doi:10.1111/ j.1537-2995.2006.00976.x

[Full text links] [CrossRef] [PubMed] [Google Scholar] [Scopus] [WoS]

33. Gange P. The evolution of bonding in orthodontics. Am J Orthod Dentofacial Orthop. 2015;147(4 Suppl):S56-S63. doi:10.1016/j.ajodo.2015.01.011.

[Full text links] [CrossRef] [PubMed] [Google Scholar] [Scopus] [WoS]

34. Zachrisson BU. Interdental papilla reconstruction in adult orthodontics. World J Orthod. 2004;5(1):67-73.

[Full text links] [PubMed] [Google Scholar] [Scopus]

35. Chudasama D, Sheridan JJ. Guidelines for contemporary airrotor stripping. J Clin Orthod. 2007:41(6):315-320.

[Full text links] [PubMed] [Google Scholar] [Scopus]

36. Sharma NS, Shrivastav SS, Hazarey PV. Mastering

interproximal stripping: with innovations in slenderization. Int J Clin Pediatr Dent. 2012;5(2):163-166. doi:10.5005/jpjournals-10005-1159.

[Full text links] [CrossRef] [PubMed] [Google Scholar]

37. Wichelhaus A, Brauchle G, Mertmann M, Sander FG. Corrosion of orthodontic pliers using different sterilization procedures. $J$ Orofac Orthop. 2004;65(6):501-511. doi:10.1007/s00056-004-

0417-9.

[CrossRef] [PubMed] [Google Scholar] [Scopus]

38. Jeffries $\mathrm{CL}$, von Fraunhofer JA. The effects of $2 \%$ alkaline gluteraldehyde solution on the elastic properties of elastomeric chain. Angle Orthod. 1991;61(1):26-30. doi:10.1043/00033219(1991)061<0026:TEOAGS>2.0.CO;2.

[Full text links] [PubMed] [Google Scholar] [Scopus] [WoS]

39. Day CJ, Price R, Sandy JR, Ireland AJ. Inhalation of aerosols produced during the removal of fixed orthodontic appliances: a comparison of 4 enamel cleanup methods. $A m$ J Orthod Dentofacial Orthop. 2008;133(1):11-17. doi:10.1016/j. ajodo.2006.01.049.

[CrossRef] [PubMed] [Google Scholar] [WoS]

40. Cochrane NJ, Ratneser S, Woods MG, Reynolds EC. Effect of different orthodontic adhesive removal techniques on sound, demineralized and remineralized enamel [published correction appears in Aust Dent J. 2014 Jun;59(2):278. Woods, MG [added]. Aust Dent J. 2012;57(3):365-372. doi:10.1111/j.18347819.2012.01713.x

[Full text links] [CrossRef] [PubMed] [Google Scholar]

41. Miksić M, Slaj M, Mestrović S. Stereomicroscope analysis of enamel surface after orthodontic bracket debonding. Coll Antropol. 2003;27 Suppl 2:83-89.

[Full text links] [PubMed] [Google Scholar] [Scopus] [WoS] 42. Arnone R. Bonding orthodontic lower 3 to 3 retainers with a rubber dam: a second generation step-by-step procedure. $A m$ J Orthod Dentofacial Orthop. 1999:116(4):432-434 doi:10.1016/ s0889-5406(99)70229-5.

[CrossRef] [PubMed] [Google Scholar] [Scopus] [WoS

43. Egli F, Bovali E, Kiliaridis S, Cornelis MA. Indirect vs direct bonding of mandibular fixed retainers in orthodontic patients: comparison of retainer failures and posttreatment stability. A 2-year follow-up of a single-center randomized controlled trial. Am J Orthod Dentofacial Orthop. 2017;151(1):15-27. doi:10.1016/j. ajodo.2016.09.009.

[Full text links] [CrossRef] [PubMed] [Google Scholar] [Scopus] [WoS]

\section{Letizia PERILLO}

MD, MS, PhD, Professor, Head, Dean Multidisciplinary Department of Medical-Surgical and Dental Specialties School of Dentistry University of Campania Luigi Vanvitelli Naples, Italy

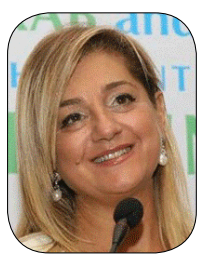

Letizia Perillo is full Professor and Dean of the School of Dentistry, University of Campania Luigi Vanvitelli, Naples (Italy). She is Visiting Professor at the University of Alabama (USA) and of Alexandria (Egypt). She was elected President of the Italian Society of Orthodontics (2021), of the Mediterranean Orthodontic Integration Project (2022), and International Ambassador of the American Association of Orthodontists (2018-2020). She is a member of many international dental organizations and of the Editorial Board of several journals. She graduated in Medicine and Surgery and specialized in Orthodontics at the University of Naples Federico II. She completed a postgraduate fellowship at the University of Michigan and a PhD in Interceptive Orthodontics at the University of Florence. She is authored several publications and she is speaker at international courses and congresses. 


\section{Questions}

\section{Dental aerosol generating procedures (AGPs) are associated with:}

$\square$ a. The use of ultrasonic instruments;

ab. Air/water syringe;

ac. Handpieces;

ud. All of them.

\section{When was Covid-19 declared a pandemic by the World Health Organization (WHO)?}

Da. On January 31th, 2020;

ab. On February 11th, 2020;

Dc. On March 11th, 2020;

ad. On April 12th, 2020.

3.Which dilution of sodium hypochlorite is effective for the disinfection of irreversible hydrocolloid impressions?

Da. 1:10;

Db. 2:10;

ac. 3:10;

ad. 4:10.

\section{Which is the diameter of particles that can reach the alveoli?}

Da. From $0.1 \mu \mathrm{m}$ to $1 \mu \mathrm{m}$;

ab. From $1 \mu \mathrm{m}$ to $10 \mu \mathrm{m}$;

ac. From $10 \mu \mathrm{m}$ to $100 \mu \mathrm{m}$;

口d. $>100 \mu \mathrm{m}$.

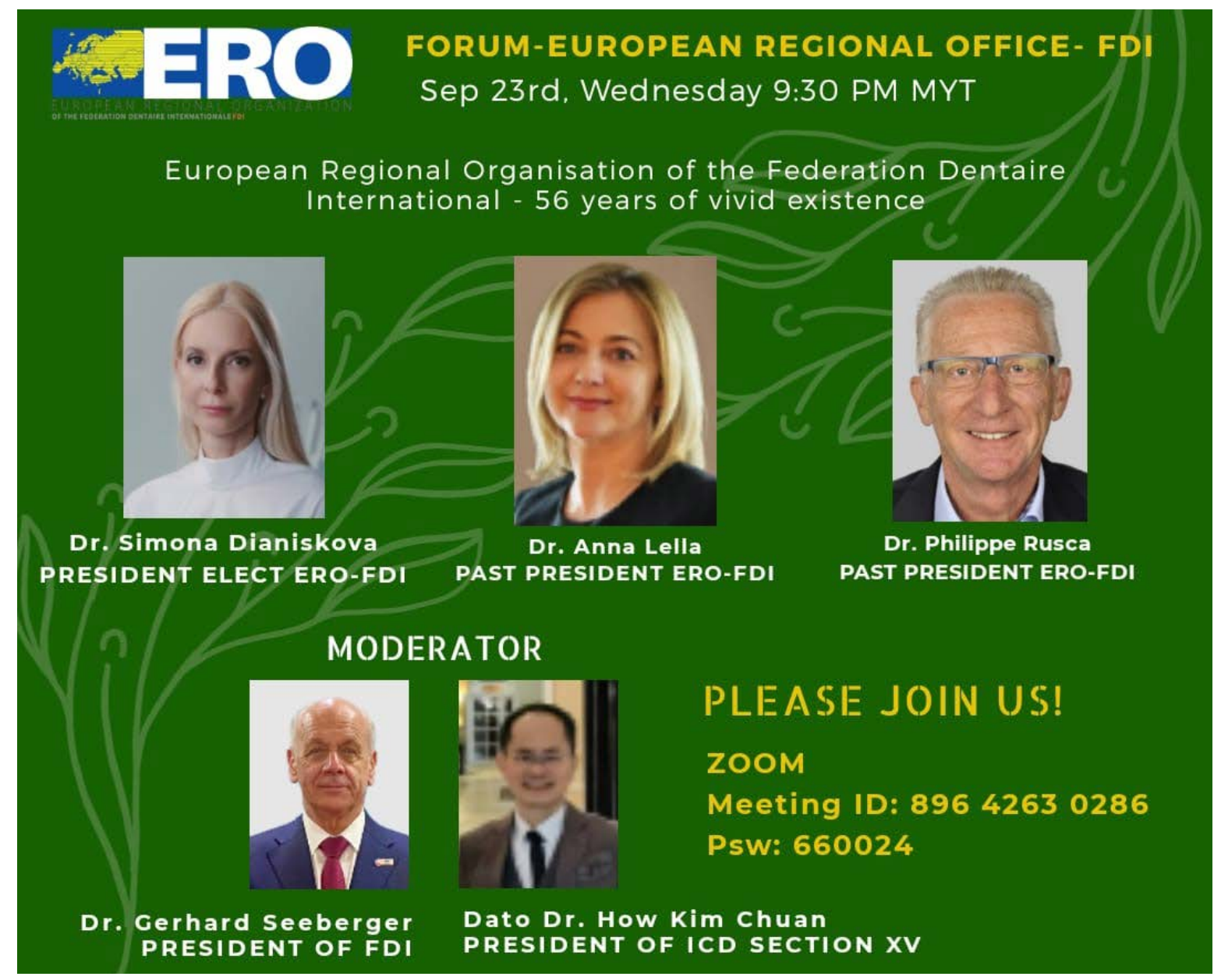

